\title{
A multicenter evaluation of the efficacy and duration of action of alcaftadine $0.25 \%$ and olopatadine $0.2 \%$ in the conjunctival allergen challenge model
}

This article was published in the following Dove Press journal:

Journal of Asthma and Allergy

9 April 2013

Number of times this article has been viewed

\author{
Stacey Ackerman' \\ Francis D'Ambrosio $\mathrm{Jr}^{2}$ \\ Jack V Greiner ${ }^{3}$ \\ Linda Villanueva ${ }^{4}$ \\ Joseph B Ciolino ${ }^{5}$ \\ David A Hollander ${ }^{4}$ \\ 'Philadelphia Eye Associates, \\ Philadelphia, PA, ²D'Ambrosio Eye \\ Care, Lancaster, MA, ${ }^{3}$ Schepens Eye \\ Research Institute, Massachusetts Eye \\ and Ear Infirmary, Harvard Medical \\ School, Boston, MA, ${ }^{4}$ Allergan, Inc, \\ Irvine, CA, ${ }^{5}$ Massachusetts Eye and \\ Ear Infirmary, Boston, MA, USA
}

Background: The purpose of this study was to evaluate the efficacy and duration of action of once-daily dosing with alcaftadine $0.25 \%$ ophthalmic solution and olopatadine $0.2 \%$ ophthalmic solution as compared with placebo in the prevention of ocular itching, and to directly compare the efficacy of alcaftadine $0.25 \%$ with olopatadine $0.2 \%$ in the prevention of ocular itching associated with allergic conjunctivitis using the conjunctival allergen challenge model.

Methods: Subjects with allergic conjunctivitis $(\mathrm{n}=127)$ were enrolled in a multicenter, double-masked, randomized, active-controlled and placebo-controlled clinical trial. Using the conjunctival allergen challenge model, this study was conducted over the course of approximately 5 weeks. Subjects were randomized into one of three treatment arms: alcaftadine $0.25 \%$ ophthalmic solution, olopatadine $0.2 \%$ ophthalmic solution, or placebo. Study medications were administered twice over the course of the trial. The primary efficacy measure for the study was ocular itching evaluated by the subject at 3,5, and 7 minutes post challenge. Secondary endpoints, measured at 7, 15, and 20 minutes post challenge, included conjunctival, ciliary, and episcleral redness, lid swelling, chemosis, and tearing. Duration of action was measured at 16 and 24 hours post-instillation of the study medication at visits 3 and 4, respectively.

Results: For the primary measure of ocular itching, both actives, alcaftadine $0.25 \%$ and olopatadine $0.2 \%$, were statistically superior to placebo at all three measured time points for both the 16-hour and 24-hour measures $(P<0.0001)$. Eyes treated with alcaftadine $0.25 \%$ had numerically lower mean ocular itching scores than eyes treated with olopatadine $0.2 \%$ at every time point, and this difference was statistically significant at the 3-minute time point 16 hours post instillation $(P=0.026)$. Eyes treated with alcaftadine $0.25 \%$ and with olopatadine $0.2 \%$ displayed significantly less lid swelling relative to placebo at every time point for the 16-hour and 24-hour post-instillation visits $(P<0.005)$. Alcaftadine $0.25 \%$ was the only active treatment that provided statistically significant relief of chemosis at every time point of the 24-hour post-instillation visit.

Conclusion: Both the alcaftadine $0.25 \%$ and olopatadine $0.2 \%$ ophthalmic solutions provided highly effective relief of ocular itching at both 16 and 24 hours post-instillation. Treatment differences between the actives were most pronounced at the earliest time point ( 3 minutes post-challenge) following conjunctival allergen challenge (16 hours), when alcaftadine $0.25 \%$ ophthalmic solution was statistically superior to olopatadine $0.2 \%$ ophthalmic solution. Alcaftadine $0.25 \%$ was the only treatment to provide significant relief from chemosis at both 16 and 24 hours post-instillation. Both active treatments and placebo were generally safe and well tolerated.

Keywords: alcaftadine $0.25 \%$, olopatadine $0.2 \%$, conjunctival allergen challenge model

\section{Introduction}

Allergic conjunctivitis is the most common allergic disorder of the eye, with an estimated 60 million affected individuals in the US. ${ }^{1}$ The hallmark symptom of the
Correspondence: Stacey L Ackerman Philadelphia Eye Associates, 1703 South Broad Street Suite 103, Philadelphia, PA 19148 , USA

Tel + I 2153398100

Email staceyackermanmd@aol.com 
disease is ocular itching, but patients typically experience a combination of conditions including conjunctival hyperemia, lid swelling, excessive tearing, chemosis, rhinorrhea, and nasal congestion. ${ }^{2}$ Affected individuals are those with either seasonal or perennial allergies. Exposure to allergens, such as pollens, dust mites, or animal dander elicits an IgEbased hypersensitivity response. This triggers the release of histamine and other pro-allergic and pro-inflammatory mediators. $^{2}$

Mast cells of the immune system are found throughout the body, including the substantia propria of the conjunctiva. ${ }^{3}$ Allergen binding to specific IgE molecules triggers mast cell degranulation and the subsequent increase in histamine leads to activation of both $\mathrm{H}_{1}$-type and $\mathrm{H}_{2}$-type histamine receptors. $^{2-4}$ These stimulate itching and vasodilation, respectively, thereby initiating a response that may last minutes or hours. With prolonged or repeated allergen exposure, the conjunctiva may become infiltrated by inflammatory cells that promote continued symptoms and eventual disruption of epithelial integrity. ${ }^{5}$

Antihistamines remain at the forefront of the therapeutic options for treating allergic conjunctivitis because of the central role of histamine in the pathogenesis of both itching and vasodilation. Currently available antagonists of histamine receptor activation have significant benefit in relieving the signs and symptoms of allergic conjunctivitis, and are particularly effective in relieving ocular itching. ${ }^{4}$ Another advantage of these compounds is that many can be formulated for topical delivery, reducing the adverse effects associated with systemic formulations. ${ }^{6,7}$ Two topical antihistamines currently approved for once-daily use in the US, olopatadine hydrochloride $0.2 \%$ and alcaftadine $0.25 \%$, are the focus of the study reported herein.

Both olopatadine $0.2 \%$ and alcaftadine $0.25 \%$ are classified as dual-action antiallergic medications, meaning they act both directly to inhibit histamine receptor activation and indirectly to reduce allergic responses by attenuating mast cell degranulation. ${ }^{4,7}$ Olopatadine was first used in a formulation strength of $0.1 \%$ and indicated for twicedaily use. A more concentrated formulation of $0.2 \%$ was later approved for once-daily treatment of ocular itching associated with allergic conjunctivitis. ${ }^{8}$ Alcaftadine $0.25 \%$ ophthalmic solution was approved by the FDA in 2011 as a once-daily therapeutic treatment for the prevention of itching associated with allergic conjunctivitis. ${ }^{9}$ These are the only topical antihistamines with this long duration of action currently available.
Olopatadine $0.2 \%$ and alcaftadine $0.25 \%$ approvals for once-daily use in the US were based upon clinical trials in which efficacy was demonstrated 16 hours post-instillation utilizing the conjunctival allergen challenge (CAC) model of allergic conjunctivitis. ${ }^{10,11}$ The CAC model provides a controlled alternative to environmental allergy trials that depend on variable allergen exposures and subjective patient-reported efficacy measures. It has been utilized in over 100 clinical trials, and has become a standard for the US Food and Drug Administration approval of ophthalmic antiallergics. ${ }^{12}$ The goal of this study was to evaluate the efficacy of once-daily antihistamines beyond the established 16-hour post-instillation time point. This study was designed to evaluate the efficacy and duration of action of alcaftadine $0.25 \%$ ophthalmic solution and olopatadine $0.2 \%$ ophthalmic solution as compared with placebo in the prevention of ocular itching at both 16 and 24 hours post instillation, and to directly compare the efficacy of alcaftadine $0.25 \%$ with olopatadine $0.2 \%$ in the prevention of ocular itching associated with allergic conjunctivitis using CAC.

\section{Materials and methods Study design}

This study (ClinicalTrials.gov identifier NCT01470118) protocol employed a multicenter, double-masked, randomized, active-controlled and placebo-controlled design. Key features of the protocol design are similar to those in previous studies of alcaftadine, ${ }^{11}$ with key differences based on the timing of allergen challenge relative to instillation of study medication; allergen challenges were conducted 16 and 24 hours after treatment instillation to assess treatment efficacy.

Three treatments were used in this comparative study. The two actives were alcaftadine $0.25 \%$ ophthalmic solution $\left(\right.$ Lastacaft $^{\circledR}$, Allergan Inc, Irvine, CA, USA) and olopatadine $0.2 \%$ ophthalmic solution (Pataday ${ }^{\mathrm{TM}}$, Alcon Laboratories Inc, Fort Worth, TX, USA), and the placebo was $0.3 \%$ hydroxypropyl methylcellulose (Tears Naturale ${ }^{\circledR}$ II, Alcon Laboratories Inc). The protocols and informed consent were both investigational review board-approved (Alpha IRB, San Clemente, CA, USA). Three sites were used for the trials and they were conducted in accordance with International Conference on Harmonisation, Good Clinical Practice guidelines and the Declaration of Helsinki. All subjects had to be at least 10 years of age, and had to provide written, informed consent (and assent if applicable). 


\section{Eligibility criteria}

Key subject inclusion was based upon entry criteria outlined as follows: subjects were required to have a history of ocular allergies and at least one positive skin test to at least one of the allergens which included cat hair, cat dander, grasses, ragweed, dog dander, cockroach, dust mites, and trees within 24 months of the trial start date. All subjects were also required to have best-corrected visual acuity $\geq 0.6$ on the $\log$ MAR (Early Treatment Diabetic Retinopathy Study chart, ETDRS) scale, and all agreed to avoid disallowed medication and contact lens wear for the designated period. Subjects underwent two allergen challenge visits during screening. In order to be included in the trial, subjects were required to exhibit a positive, bilateral reaction (itching and conjunctival redness scores $\geq 2$, see below) to the $\mathrm{CAC}$ within 10 minutes of allergen instillation at both visit 1 and visit 2 .

Key exclusion criteria included any baseline itching or redness $>1$ in any vessel at each visit, any known allergy, contraindications or sensitivity to any of the study medications, or any systemic or ocular condition in the opinion of the investigator that could have affected safety or trial parameters. Exclusion criteria also included ocular surgery within 3 months or refractive surgery within 6 months, or if subjects exhibited any signs of active allergic conjunctivitis at the start of any visit, had an active ocular infection (bacterial or viral), or history of herpetic ocular disease. The use of any prohibited topical or systemic medications during the designated period or concurrent enrollment in any other clinical trial excluded the subject from the study. Due to the potential for randomization into a treatment arm with a pregnancy category $\mathrm{C}$ therapeutic, ${ }^{8}$ women who were pregnant, planning a pregnancy, lactating, or not using a medically acceptable form of birth control for the entire period of the trial were excluded from the study. Subjects planning surgical procedures during the trial period or with a history of retinal detachment, diabetic retinopathy, or progressive retinal disease were also ineligible. Based upon these inclusion and exclusion criteria, three study sites screened a total of 245 subjects. A total of 127 subjects were eligible for randomization in a 1:1:1 ratio corresponding to the three treatments.

\section{Allergen challenge and assessment of treatment efficacy}

Allergen challenge employed a five-point scale for severity of ocular itch, where 0 indicated no itch and 4 indicated an incapacitating itch with an insatiable desire to rub. This scale, which allows for half-unit measures, has been used in CAC studies previously. ${ }^{10-18}$ Ocular redness was scored by an investigator using a five-point ocular redness scale $(0-4)$ where $0=$ none and $4=$ extremely severe with large, numerous, dilated blood vessels characterized by an unusually severe deep red color. This scale has been used to grade ocular redness in previous studies. ${ }^{10-18}$

For the first study visit (visit 1), subjects received bilateral ocular instillation of antigen, followed by subject-reported assessment of itching 10 minutes after instillation. Subjects were titrated with increasing allergen concentrations until the scores for both itching and redness reached $\geq 2$.0. The maximal allergen concentration used in the visit 1 titration was used for all subsequent visits. All study visits included medical history updates and ocular health assessment (visual acuity measurement and slit-lamp examination).

At visit 2, a second allergen challenge provided baseline data for those subjects who continued to satisfy eligibility criteria. Following the challenge, subjects graded their ocular itching at 3,5, and 7 minutes after allergen instillation, while the secondary endpoint measures of investigator-assessed conjunctival redness and chemosis and subject-assessed lid swelling and tearing were at 7 , 15 , and 20 minutes. Subjects who met the screening criteria (scores $\geq 2$ for both itching and conjunctival redness within 10 minutes of CAC) at visit 2 continued to visit $3 \mathrm{~A}$, approximately 2 weeks after visit 2 .

At visit $3 \mathrm{~A}$, subjects who qualified were randomized and received one drop of masked treatment (either alcaftadine $0.25 \%$, olopatadine $0.2 \%$, or placebo) in each eye. Subjects returned approximately 15.5 hours after treatment instillation for the visit 3B CAC. Sixteen hours after instillation of treatment, subjects' eyes were challenged by instilling one drop of the allergen solution bilaterally. Ocular itching was graded by subjects at 3,5, and 7 minutes after instillation. Secondary efficacy variables, ie, redness, chemosis, tearing, and lid swelling, were evaluated at 7, 15, and 20 minutes. Conjunctival, ciliary, and episcleral redness as well as chemosis were graded by the investigator, and lid swelling and tearing were graded by the subject.

Fourteen days later ( \pm 3 days), subjects returned for visit 4A. Following ocular health assessments, study staff instilled one drop of masked treatment into each eye and the subjects returned in 23.5 hours for visit 4B. Twenty-four hours after treatment instillation, subjects were again challenged with one drop of allergen solution bilaterally and then assessed for primary and secondary variables as in previous visits. 


\section{Efficacy and safety measures}

The primary efficacy variable was ocular itching, which was quantified by the subjects using a 5-unit ( $0-4$ units) standardized scale, with half-unit increments allowed. Secondary endpoints of conjunctival redness, ciliary redness, episcleral redness, and chemosis, were graded by the investigator using a $0-4$ scale in which half unit values were allowed. Lid swelling employed a 0-3 scale without half-unit increments, and ocular tearing was scored using a $0-4$ scale without half-unit increments. Safety assessments included the visual acuity measure using an ETDRS chart, slit-lamp biomicroscopy examination, and adverse event assessments.

\section{Data analysis and statistical methods}

Study population information and medical histories included both quantitative data such as age and qualitative demographics. Quantitative data were analyzed using a two-sided $t$-test, while qualitative demographic variables were analyzed using Fisher's Exact test or Chi-squared test. The intent-to-treat population (Table 1) was defined as those who were randomized at the beginning of visit 3 . Per protocol subjects were those who completed the study with no major protocol violations.

The primary efficacy measure was ocular itching and the primary endpoint was mean ocular itching at 16 and 24 hours post instillation of the study medication, and 3, 5, and 7 minutes post CAC. Data collected at visit $3 \mathrm{~B}$ and visit $4 \mathrm{~B}$ were used for analysis of the primary endpoint. Predefined analysis of the primary efficacy data included comparison of the number of subjects in each treatment group with minimal itch, defined as those with itch scores $<1$, and the number of subjects with zero itch, defined as scores $=0$. These analyses used Fisher's Exact test for each pairwise treatment comparison (alcaftadine $0.25 \%$ versus placebo, olopatadine $0.2 \%$ versus placebo, and alcaftadine $0.25 \%$ versus olopatadine $0.2 \%$ ). Descriptive statistics (number of observations, mean, standard deviation, median, minimum, and maximum values) for the primary efficacy variable were summarized by visit, time point, and treatment group. Secondary endpoints were summarized using descriptive statistics and analyzed using the same statistical methods as those used for the primary endpoints.

A sample size of 40 subjects in each treatment group was determined to provide approximately $99 \%$ power to detect a difference in means of 1.00 unit (the difference between placebo and alcaftadine $0.25 \%$, and the difference between placebo and olopatadine $0.2 \%$ ) assuming that the common standard deviation is 1.00 unit using a two-sample $t$-test with a 0.05 two-sided significance level. A sample size of 40 subjects in each treatment group was determined to provide approximately $87 \%$ power to detect a difference in means of 0.70 unit between alcaftadine $0.25 \%$ and olopatadine $0.2 \%$.

\section{Results}

A total of 127 subjects were enrolled in the study following screening visits 1 and 2, and 115 completed the study. Both

Table I Demographics (intent-to-treat population)

\begin{tabular}{|c|c|c|c|c|c|}
\hline Characteristic & $\begin{array}{l}\text { Alcaftadine } 0.25 \% \\
n=43\end{array}$ & $\begin{array}{l}\text { Olopatadine } 0.2 \% \\
n=43\end{array}$ & $\begin{array}{l}\text { Placebo } \\
n=4 I\end{array}$ & $\begin{array}{l}\text { All subjects } \\
n=127\end{array}$ & $P$ value \\
\hline Age & & & & & 0.634 \\
\hline Mean \pm SD & $39.3 \pm 12.4$ & $37.0 \pm 14.8$ & $39.3 \pm 12.3$ & $38.5 \pm 13.2$ & \\
\hline Min-max & $15-64$ & $12-74$ & $|4-6|$ & $12-74$ & \\
\hline Gender, n (\%) & & & & & 0.726 \\
\hline Male & $12(28)$ & $10(23)$ & $13(32)$ & $35(28)$ & \\
\hline Female & $31(72)$ & $33(77)$ & $28(68)$ & $92(72)$ & \\
\hline Ethnicity, n (\%) & & & & & 0.496 \\
\hline Hispanic or Latino & $5(11.6)$ & $9(20.9)$ & $5(12.2)$ & $19(15)$ & \\
\hline Not Hispanic or Latino & $38(88.4)$ & $34(79.1)$ & $36(87.8)$ & $108(85)$ & \\
\hline Race, $n$ & & & & & 0.316 \\
\hline African American & 5 & 2 & 6 & 13 & \\
\hline Caucasian & 34 & 34 & 33 & 101 & \\
\hline Other & 4 & 7 & 2 & 13 & \\
\hline Iris color, $\mathrm{n}$ & & & & & 0.062 \\
\hline Blue & 20 & 24 & 16 & 60 & \\
\hline Brown & 50 & 46 & 46 & 142 & \\
\hline Hazel & 4 & 12 & 6 & 22 & \\
\hline Green & 12 & 4 & 12 & 28 & \\
\hline Gray & 0 & 0 & 2 & 2 & \\
\hline
\end{tabular}

Abbreviations: min, minimum; max, maximum; $P$, probability level; SD, standard deviation. 
A

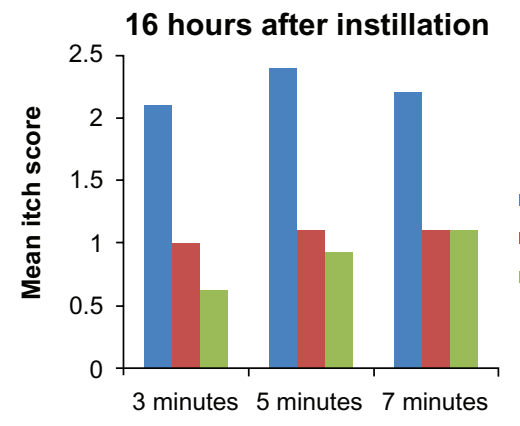

B

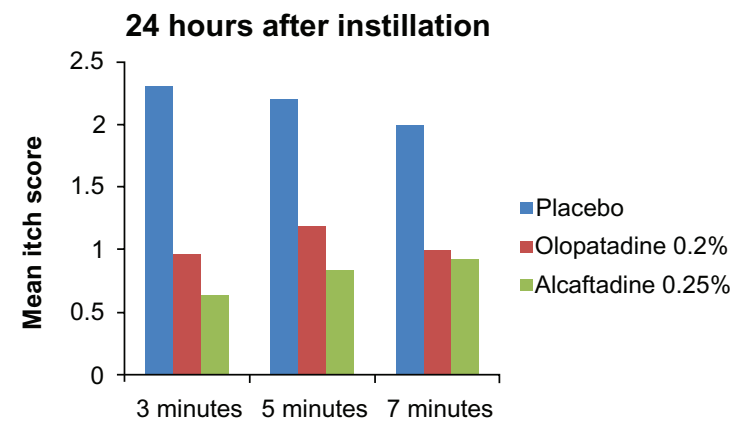

Figure I Comparison of ocular itching scores at 16 hours (A) and at 24 hours (B) after instillation of treatment. Mean itching for placebo, alcaftadine $0.25 \%$, and olopatadine $0.2 \%$ at 3,5 , and 7 minutes after allergen challenge.

active treatment arms had $38(88 \%)$ subjects complete the study, and 39 (95\%) completed in the placebo group. Of the 127 subjects enrolled in the intent-to-treat population, 12 subjects did not complete the study; of these, three were because of non-treatment-related adverse events, eight because of administrative issues, and two because of other non-study-related issues. The demographic characteristics of the groups revealed no significant differences between treatment groups with respect to age, gender, race, or iris color (Table 1).
A

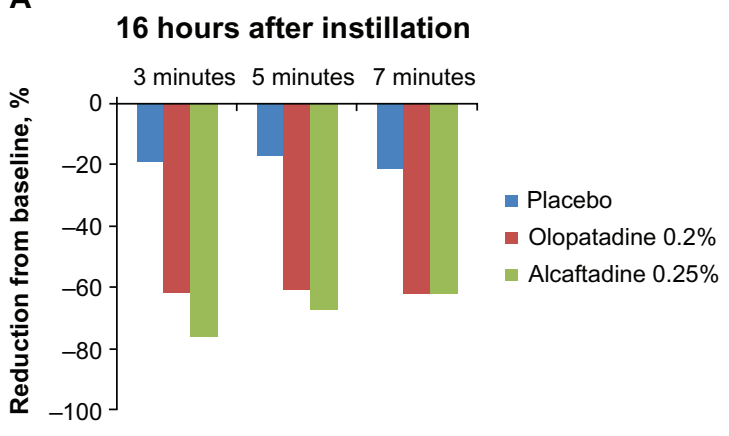

B

\section{4 hours after instillation}

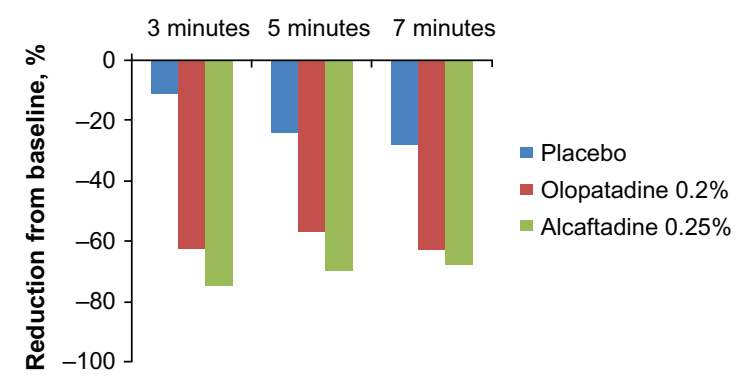

Figure 2 Reduction from baseline itch scores. A comparison of itch scores at visit 3 ( 16 hours; A) and at visit 4 (24 hours; B) with those from visit 2 (pretreatment baseline visit).

The primary endpoint for this study was mean ocular itching at 3, 5, and 7 minutes post CAC at 16 and 24 hours post instillation of treatment (Figure 1; Table 2). Sixteen hours after treatment instillation, both actives were statistically superior to placebo $(P<0.0001)$. The same statistical superiority compared with placebo was observed for active treatments 24 hours after instillation $(P<0.0001)$. Comparison of the two actives demonstrated that alcaftadine $0.25 \%$ achieved numerically lower mean itch scores than olopatadine $0.2 \%$ at all

Table 2 Summary of ocular itching results (intent-to-treat population): differences versus placebo in mean ocular itching scores following CAC for alcaftadine $0.25 \%$ and olopatadine $0.2 \%$ at 16 and 24 hours

\begin{tabular}{|c|c|c|c|c|c|c|}
\hline \multirow[t]{3}{*}{ Time point post-CAC } & \multicolumn{3}{|l|}{ Visit 3} & \multicolumn{3}{|l|}{ Visit 4} \\
\hline & \multicolumn{3}{|c|}{$\begin{array}{l}\text { Duration of action } 16 \text { hours following study } \\
\text { treatment }\end{array}$} & \multicolumn{3}{|c|}{$\begin{array}{l}\text { Duration of action } 24 \text { hours following study } \\
\text { treatment }\end{array}$} \\
\hline & $3 \mathrm{~min}$ & $5 \mathrm{~min}$ & $7 \mathrm{~min}$ & $3 \mathrm{~min}$ & $5 \mathrm{~min}$ & $7 \mathrm{~min}$ \\
\hline \multicolumn{7}{|l|}{ Active versus placebo } \\
\hline Alcaftadine-placebo & -1.53 & -1.43 & -1.13 & -1.63 & -1.35 & -1.02 \\
\hline$P$ value & $<0.0001$ & $<0.0001$ & $<0.0001$ & $<0.0001$ & $<0.0001$ & $<0.0001$ \\
\hline Olopatadine-placebo & -1.14 & -1.22 & -1.08 & -1.30 & -1.03 & -0.94 \\
\hline$P$ value & $<0.0001$ & $<0.0001$ & $<0.0001$ & $<0.0001$ & $<0.0001$ & $<0.000$ I \\
\hline \multicolumn{7}{|l|}{ Active versus active } \\
\hline Alcaftadine-olopatadine & -0.39 & -0.20 & -0.05 & -0.33 & -0.32 & -0.08 \\
\hline$P$ value & 0.026 & 0.273 & 0.798 & 0.073 & 0.117 & 0.710 \\
\hline
\end{tabular}

Abbreviations: CAC, conjunctival allergen challenge; min, minutes; $P$, probability level. 
time points, both at 16 hours (Figure 1A) and 24 hours post instillation (Figure 1B), with a statistically significant difference at the 3 -minute time point at 16 hours $(P=0.026$; Table 2$)$.

To assess the ability of the actives to reduce ocular itching within a population, comparisons between baseline itch scores for each treatment group (visit 2) and scores obtained in visits 3 and 4 were made; in this comparison, the observed treatment effects are responses in the same subjects at different visits rather than a parallel placebo population. The percent itch reduction from baseline at both 16 and 24 hours after treatment instillation revealed significant reductions from baseline (Figure 2).

The percentage of subjects reporting minimal itch (a score of $<1.0$ ), is plotted for all treatments at both the 16 and 24 hour assessments (Figure 3 ). The difference between actives was greatest at 3 minutes ( 16 hours after instillation), when $78 \%$ of subjects treated with alcaftadine $0.25 \%$ reported itch scores $<1$ as compared with $46 \%$ of those treated with olopatadine $0.2 \%(P=0.006)$. At the same time point at 24 hours post instillation, $71 \%$ of subjects treated with alcaftadine $0.25 \%$ reported minimal itch, compared with $47 \%$ of subjects treated with olopatadine $0.2 \%(P=0.061)$.

The percentage of subjects reporting complete relief (itch score $=0$ ) was also examined at both 16 and 24 hours after treatment instillation (Figure 4). Both actives exhibited a zero itch score in $20 \%-30 \%$ of subjects. A greater number of subjects in the alcaftadine $0.25 \%$ arm displayed zero itch at 3 minutes $(P \geq 0.192)$, while more subjects in the olopatadine $0.2 \%$ arm had zero itch at the 7 -minute time point ( $P \geq 0.756$ ), although differences in zero itch were not statistically significant.

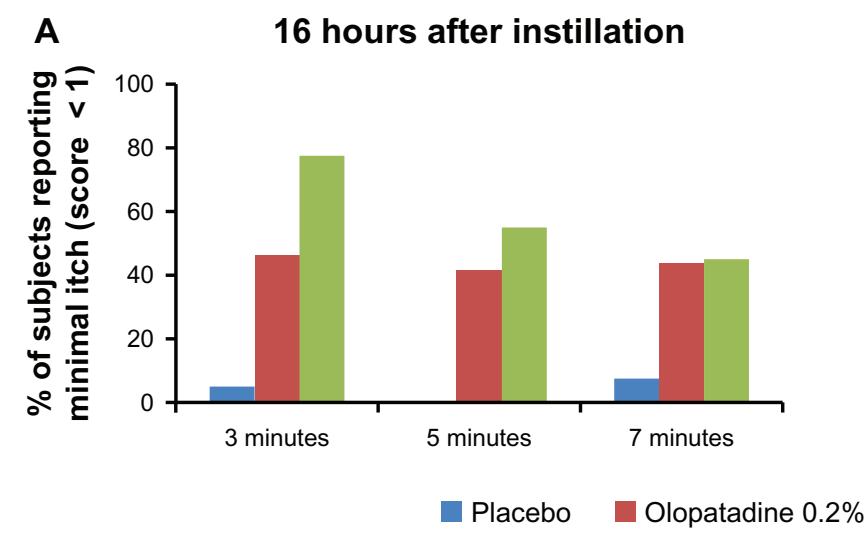

An alternative approach to the assessment of itch relief is to examine a distribution of the raw subject-reported itch scores (Figure 5). For each visit, subjects reported a total of six scores for two eyes at three time points. For subjectreported itch score distributions, a leftward shift in score frequencies from baseline to drug treatment is an indicator of efficacy, both in terms of the degree of relief and the proportion of subjects whose symptoms are alleviated. In this study, the leftward shift seen in the alcaftadine group is greater than that seen in the olopatadine group, at both 16 and 24 hours after instillation.

Secondary efficacy measures for redness, chemosis, lid swelling, and tearing are summarized in Table 3. For conjunctival redness measures, both actives demonstrated statistical significance relative to placebo in each of the three vascular beds at some but not all time points evaluated, and there were no significant differences between actives (Table 3 ). Both treatments provided statistically significant reductions in lid swelling and ocular tearing compared with placebo, and these effects were significant at both 16 and 24 hours after treatment instillation (Table 3 ). For chemosis, both alcaftadine $0.25 \%$ and olopatadine $0.2 \%$ provided relief 16 hours after instillation, but only alcaftadine $0.25 \%$ demonstrated statistical significance against placebo for chemosis at every time point measured at 24 hours.

There were no serious adverse events in the course of this 5-week study. There was a total of 14 adverse events experienced by nine subjects, and five of these events were reported by one subject. Three of these occurred as a result of a fall, and were not treatment-related. None of the reported adverse events were related to any study treatments.

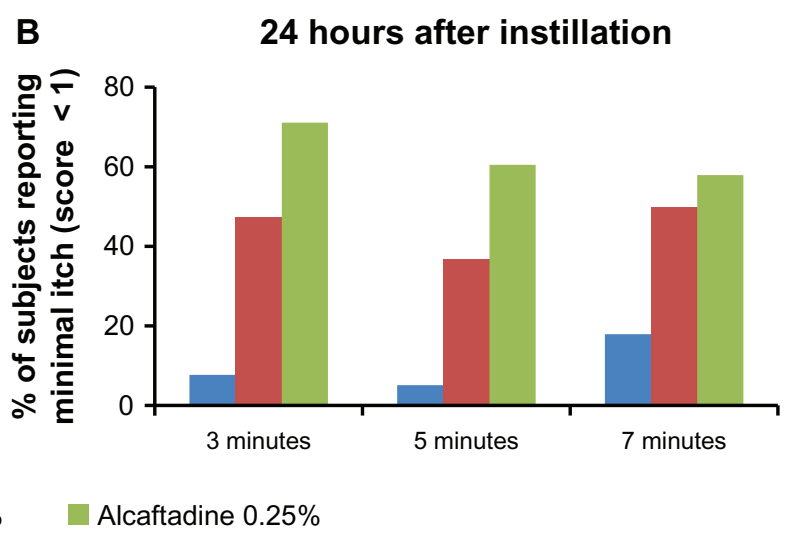

Figure 3 Comparison of minimal itch (scores $<1$ ) data for placebo, alcaftadine $0.25 \%$, and olopatadine $0.2 \%$ at 16 hours $(\mathbf{A})$ and at 24 hours $(\mathbf{B})$ after instillation of treatment. 

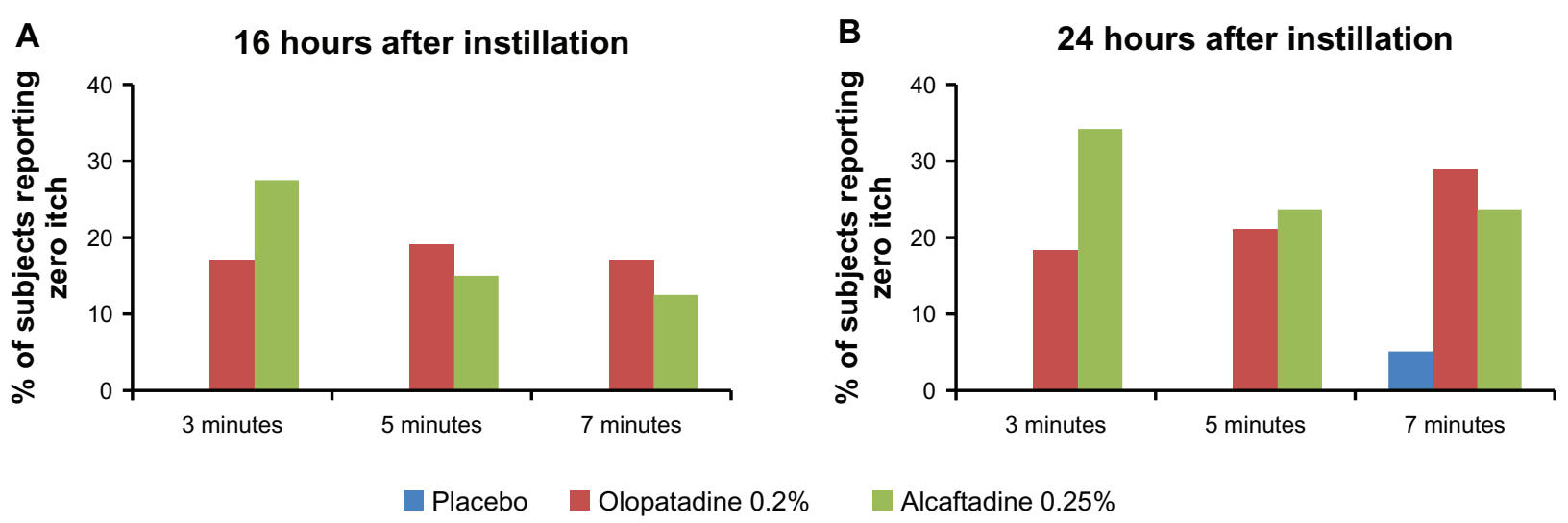

Figure 4 Comparison of zero itch data for placebo, alcaftadine $0.25 \%$, and olopatadine $0.2 \%$ at 16 hours (A) and 24 hours (B) after instillation of treatment.

A

Percent of total scores reported at baseline time points

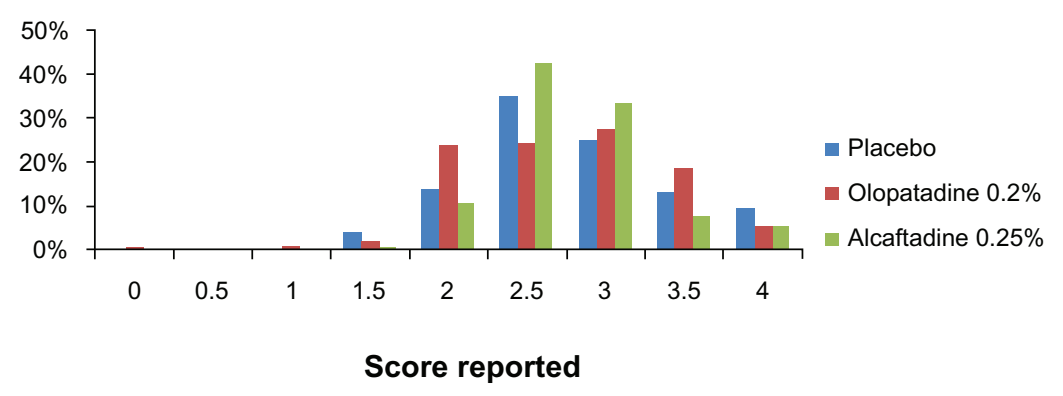

B

Percent of total scores reported at 16 -hour time points

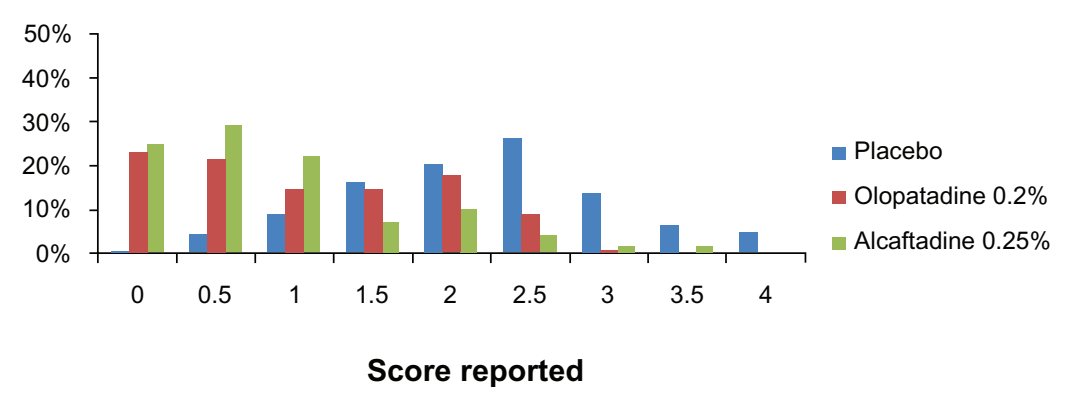

C

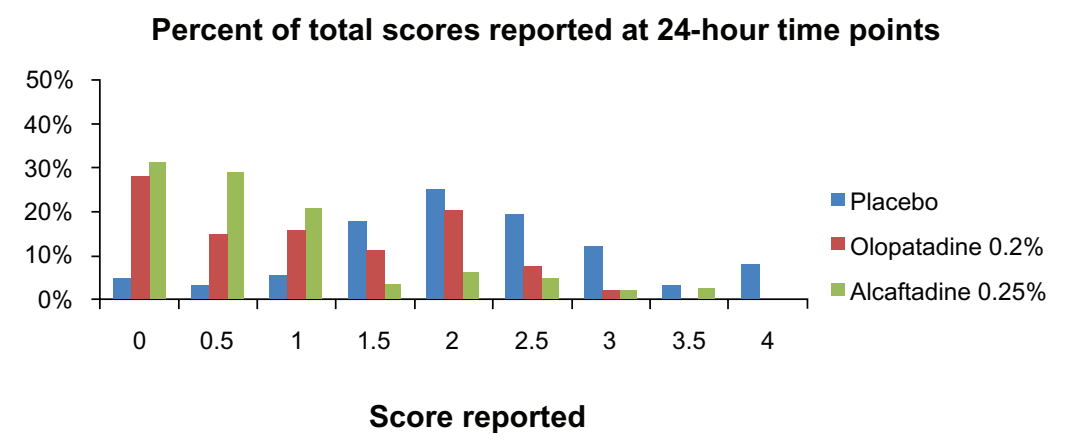

Figure 5 Percent of total subject-reported itching scores in each treatment group (A-C). 
Table 3 Secondary endpoint data for both visits expressed as difference scores

\begin{tabular}{|c|c|c|c|c|c|c|}
\hline \multirow[t]{3}{*}{ Time point post-CAC } & \multicolumn{3}{|l|}{ Visit 3} & \multicolumn{3}{|l|}{ Visit 4} \\
\hline & \multicolumn{3}{|c|}{$\begin{array}{l}\text { Duration of action } 16 \text { hours post study } \\
\text { treatment }\end{array}$} & \multicolumn{3}{|c|}{$\begin{array}{l}\text { Duration of action } 24 \text { hours post study } \\
\text { treatment }\end{array}$} \\
\hline & $7 \mathrm{~min}$ & $15 \mathrm{~min}$ & $20 \mathrm{~min}$ & $7 \mathrm{~min}$ & $15 \mathrm{~min}$ & $20 \mathrm{~min}$ \\
\hline \multicolumn{7}{|l|}{ Conjunctival redness } \\
\hline Alcaftadine $0.25 \%$-placebo & -0.21 & -0.26 & -0.24 & $-0.34^{\mathrm{a}}$ & -0.22 & -0.21 \\
\hline Olopatadine $0.2 \%$-placebo & $-0.33^{\mathrm{a}}$ & $-0.30^{\mathrm{a}}$ & -0.25 & $-0.30^{\mathrm{a}}$ & -0.21 & -0.28 \\
\hline Alcaftadine $0.25 \%$-olopatadine $0.2 \%$ & 0.11 & 0.04 & 0.01 & -0.04 & -0.01 & 0.07 \\
\hline \multicolumn{7}{|l|}{ Ciliary redness } \\
\hline Alcaftadine $0.25 \%$-placebo & $-0.43^{\mathrm{a}}$ & $-0.30^{\mathrm{a}}$ & -0.28 & $-0.48^{\mathrm{a}}$ & $-0.36^{\mathrm{a}}$ & -0.26 \\
\hline Olopatadine $0.2 \%$-placebo & $-0.45^{\mathrm{a}}$ & $-0.32^{\mathrm{a}}$ & -0.29 & $-0.36^{\mathrm{a}}$ & -0.33 & -0.28 \\
\hline Alcaftadine $0.25 \%$-olopatadine $0.2 \%$ & 0.02 & 0.02 & 0.01 & -0.12 & -0.03 & 0.02 \\
\hline \multicolumn{7}{|l|}{ Episcleral redness } \\
\hline Alcaftadine $0.25 \%$-placebo & -0.22 & -0.31 & -0.16 & $-0.36^{\mathrm{a}}$ & -0.19 & -0.22 \\
\hline Olopatadine $0.2 \%$-placebo & $-0.38^{\mathrm{a}}$ & $-0.36^{a}$ & -0.29 & $-0.45^{\mathrm{a}}$ & -0.33 & -0.35 \\
\hline Alcaftadine $0.25 \%$-olopatadine $0.2 \%$ & 0.16 & 0.06 & 0.13 & 0.09 & 0.13 & 0.13 \\
\hline \multicolumn{7}{|l|}{ Chemosis } \\
\hline Alcaftadine $0.25 \%$-placebo & $-0.35^{\mathrm{a}}$ & $-0.49^{a}$ & $-0.4 I^{\mathrm{a}}$ & $-0.25^{\mathrm{a}}$ & $-0.31^{\mathrm{a}}$ & $-0.28^{\mathrm{a}}$ \\
\hline Olopatadine $0.2 \%$-placebo & $-0.27^{\mathrm{a}}$ & $-0.42^{\mathrm{a}}$ & $-0.38^{\mathrm{a}}$ & -0.18 & -0.25 & -0.29 \\
\hline Alcaftadine $0.25 \%$-olopatadine $0.2 \%$ & -0.08 & -0.06 & -0.02 & -0.07 & -0.05 & 0.01 \\
\hline \multicolumn{7}{|l|}{ Lid swelling } \\
\hline Alcaftadine $0.25 \%$-placebo & $-0.7^{\mathrm{a}}$ & $-0.8^{\mathrm{a}}$ & $-0.7^{\mathrm{a}}$ & $-0.6^{\mathrm{a}}$ & $-0.5^{\mathrm{a}}$ & $-0.5^{\mathrm{a}}$ \\
\hline Olopatadine $0.2 \%$-placebo & $-0.5^{\mathrm{a}}$ & $-0.6^{a}$ & $-0.6^{a}$ & $-0.6^{\mathrm{a}}$ & $-0.4^{\mathrm{a}}$ & $-0.5^{\mathrm{a}}$ \\
\hline Alcaftadine $0.25 \%$-olopatadine $0.2 \%$ & -0.1 & -0.2 & -0.1 & 0.0 & -0.1 & 0.0 \\
\hline \multicolumn{7}{|l|}{ Tearing } \\
\hline Alcaftadine $0.25 \%$-placebo & $-0.6^{\mathrm{a}}$ & $-0.5^{\mathrm{a}}$ & $-0.6^{\mathrm{a}}$ & $-0.7^{\mathrm{a}}$ & $-0.4^{\mathrm{a}}$ & -0.3 \\
\hline Olopatadine $0.2 \%$-placebo & $-0.4^{a}$ & -0.3 & -0.4 & $-0.6^{\mathrm{a}}$ & -0.3 & -0.3 \\
\hline Alcaftadine $0.25 \%$-olopatadine $0.2 \%$ & -0.1 & -0.2 & -0.2 & -0.1 & -0.1 & 0.0 \\
\hline
\end{tabular}

Notes: Data are from the intent-to-treat population. ${ }^{a} P<0.005$ versus placebo using a two-sided $t$-test.

Abbreviations: CAC, conjunctival allergen challenge; min, minutes.

\section{Discussion}

In this comparative study, two topical formulations of ocular antihistamines were evaluated for their ability to provide a long duration of relief from itching due to allergic conjunctivitis. Both olopatadine $0.2 \%$ and alcaftadine $0.25 \%$ are approved by the US Food and Drug Administration for once-daily dosing. ${ }^{89}$ In previous studies, ${ }^{10,11}$ duration of action had been measured 16 hours following instillation, and both treatments demonstrated substantial relief at that time point. The study described in this report was designed to extend that analysis to 24 hours post-instillation, while also providing a basis for direct comparison of the two antiallergic agents. Our comparison of alcaftadine $0.25 \%$, olopatadine $0.2 \%$, and placebo utilized the CAC model to measure duration of treatment efficacy in reducing ocular itching, ocular redness, chemosis, tearing, and lid swelling. Use of CAC is the current standard for regulatory approval of ocular antiallergic agents in the US. ${ }^{10,11,13-18}$

Both treatments provided reduction in symptoms and signs of allergic conjunctivitis in this study. The reduction in ocular itching at 16 and 24 hours after treatment instillation was statistically significant for both olopatadine $0.2 \%$ and alcaftadine $0.25 \%$ compared with placebo $(P<0.0001)$. Eyes treated with alcaftadine $0.25 \%$ had significantly lower scores for mean ocular itching than eyes treated with olopatadine $0.2 \%$ at 3 minutes for the 16 -hour visit $(P=0.026)$, the earliest time point evaluated in the CAC model. In addition, eyes treated with alcaftadine $0.25 \%$ had numerically lower scores for mean itching than eyes treated with olopatadine $0.2 \%$ at all other time points for both the 16-hour and 24-hour visits. Both treatments also demonstrated reductions in all secondary endpoints. Alcaftadine $0.25 \%$ was statistically superior to olopatadine $0.2 \%$ for reducing chemosis 24 hours after instillation.

The differences in ocular itching scores between the actives and placebo, as well as the differences between the two actives, were similar both at the 16 -hour and 24 -hour postinstillation visits. The most significant difference between the two treatments was evidenced in the comparison of minimal itch (score $<1$ ). At the 3-minute time point (16 hours after instillation), about $78 \%$ of subjects receiving alcaftadine reported minimal or no itch; in contrast, less than $50 \%$ of 
subjects receiving olopatadine demonstrated a similar level of itch relief. The difference in efficacy is perhaps most apparent in the distribution of itch scores (Figure 5). These plots revealed an important difference between alcaftadine and olopatadine, where a greater proportion of scores for alcaftadine are $\leq 1.5$, while the scores for olopatadine are evenly distributed in a range between 0 and 2 .

Two previous studies have examined the therapeutic effects of both alcaftadine and olopatadine. An early CACbased clinical study found alcaftadine $0.25 \%$ was superior to olopatadine $0.1 \%$ for both onset and duration of anti-itch effects. ${ }^{19}$ The faster onset of effect is consistent with the findings of the present study in which statistically significant lower itch scores were seen at the 3-minute time point post allergen challenge (16 hours post instillation). In another preclinical study, alcaftadine was shown to have a greater effect than olopatadine on both eosinophil recruitment and epithelial junctional protein stability, ${ }^{20}$ suggesting a potential for greater efficacy in late-phase allergy. This result, together with an examination of inflammation-induced disruptions in ocular epithelial stability, ${ }^{21}$ suggest that efficacy differences between alcaftadine and olopatadine may be related to the greater ability of alcaftadine to prevent the disruption to the ocular surface that follows allergen exposure. Both rapid relief in ocular itching as well as long duration of action are keys to successful control of allergic conjunctivitis. Results of the current study, in combination with previous reports, establish that alcaftadine $0.25 \%$ can effectively address both of these key aspects of disease control.

Overall, this study demonstrated that both alcaftadine $0.25 \%$ and olopatadine $0.2 \%$ were effective at preventing ocular itching in a CAC model beyond 16 hours. The differences between actives and placebo and the differences between the two actives at 24 hours post instillation were similar to the findings 16 hours post instillation. Alcaftadine $0.25 \%$ was shown to achieve statistically significant lower mean ocular itch scores than olopatadine $0.2 \%$ at the earliest time point following allergen challenge. Both alcaftadine $0.25 \%$ and olopatadine $0.2 \%$ were safe and well tolerated. Further studies are warranted to delineate further the actions of these two treatments and understand better the mechanisms of actions potentially underlying any differences in efficacy.

\section{Acknowledgment}

Copy editing and styling support was provided by Diann Glickman, Evidence Scientific Solutions, and funded by Allergan Inc. The authors would like to acknowledge James
McLaughlin of Ora, Inc. for writing assistance, funded by Allergan, Inc.

\section{Disclosure}

Ms Villanueva and Dr Hollander are employees of Allergan, Inc. The authors report no other conflicts of interest in this work.

\section{References}

1. Blaiss MS. Allergic rhinoconjunctivitis: burden of disease. Allergy Asthma Proc. 2007;28(4):393-397.

2. Collum LM, Kilmartin DJ. Acute allergic conjunctivitis. In: Abelson MB, editor. Allergic Diseases of the Eye. Philadelphia, PA: WB Saunders; 2000.

3. Abelson MB, Schaefer K. Functional anatomy of the human conjunctiva and cornea. In: Abelson MB, editors. Allergic Diseases of the Eye. Philadelphia, PA: WB Saunders; 2000.

4. Abelson MB, McLaughlin JT, Gomes PJ. Antihistamines in ocular allergy: are they all created equal? Curr Allergy Asthma Rep. 2011; 11(3):205-211.

5. Hughes JL, Lackie PM, Wilson SJ, Church MK, McGill JI. Reduced structural proteins in the conjunctival epithelium in allergic eye disease. Allergy. 2006;61(11):1268-1274.

6. [No authors]. Drugs for allergic disorders. Treat Guidel Med Lett. 2010;8(90):9-18.

7. Manzouri B, Flynn TH, Larkin F, Ono SJ, Wyse R. Pharmacotherapy of allergic eye disease. Expert Opin Pharmacother. 2006;7(9): 1191-1200.

8. Pataday ${ }^{\circledR}$ (olopatadine hydrochloride ophthalmic solution) $0.2 \%$. [package insert]. Fort Worth, TX: Alcon Laboratories Inc; 1996.

9. Lastacaft ${ }^{\circledR}$ (alcaftadine ophthalmic solution) $0.25 \%$. [package insert]. Irvine, CA: Allergan Inc; 2010.

10. Abelson MB, Gomes PJ. Olopatadine $0.2 \%$ ophthalmic solution: the first ophthalmic antiallergy agent with once-daily dosing. Expert Opin Drug Metab Toxicol. 2008;4(4):453-461.

11. Torkildsen G, Shedden A. The safety and efficacy of alcaftadine $0.25 \%$ ophthalmic solution for the prevention of itching associated with allergic conjunctivitis. Curr Med Res Opin. 2011;27(3):623-631.

12. Abelson MB, Chambers WA, Smith LM. Conjunctival allergen challenge. A clinical approach to studying allergic conjunctivitis. Arch Ophthalmol. 1990;108(1):84-88.

13. Abelson MB, Torkildsen GL, Williams JI, Gow JA, Gomes PJ, McNamara TR; the Bepotastine Besilate Ophthalmic Solutions Clinical Study Group. Time to onset and duration of action of the antihistamine bepotastine besilate ophthalmic solutions $1.0 \%$ and $1.5 \%$ in allergic conjunctivitis: a phase III, single-center, prospective, randomized, double-masked, placebo-controlled, conjunctival allergen challenge assessment in adults and children. Clin Ther. 2009;31(9):1908-1921.

14. Abelson MB. Evaluation of olopatadine, a new ophthalmic antiallergic agent with dual activity, using the conjunctival allergen challenge model. Ann Allergy Asthma Immunol. 1998;81(3):211-218.

15. Abelson MB, Spitalny L. Combined analysis of two studies using the conjunctival allergen challenge model to evaluate olopatadine hydrochloride, a new ophthalmic antiallergic agent with dual activity. Am J Ophthalmol. 1998;125(6):797-804.

16. Abelson MB, Chapin MJ, Kapik BM, Shams NB. Efficacy of ketotifen fumarate $0.025 \%$ ophthalmic solution compared with placebo in the conjunctival allergen challenge model. Arch Ophthalmol. 2003;121(5): 626-630.

17. Abelson MB, Gomes P, Crampton HJ, Schiffman RM, Bradford RR, Whitcup SM. Efficacy and tolerability of ophthalmic epinastine assessed using the conjunctival antigen challenge model in patients with a history of allergic conjunctivitis. Clin Ther. 2004;26(1):35-47. 
18. Abelson MB, Spangler DL, Epstein AB, Mah FS, Crampton HJ. Efficacy of once-daily olopatadine $0.2 \%$ ophthalmic solution compared to twice-daily olopatadine $0.1 \%$ ophthalmic solution for the treatment of ocular itching induced by conjunctival allergen challenge. Curr Eye Res. 2007;32(12):1017-1022.

19. Greiner JV, Edwards-Swanson K, Ingerman A. Evaluation of alcaftadine $0.25 \%$ ophthalmic solution in acute allergic conjunctivitis at 15 minutes and 16 hours after instillation versus placebo and olopatadine $0.1 \%$. Clin Ophthalmol. 2011;5:87-93.
20. Ono SJ, Lane K. Comparison of effects of alcaftadine and olopatadine on conjunctival epithelium and eosinophil recruitment in a murine model of allergic conjunctivitis. Drug Des Devel Ther. 2011;5: 77-84.

21. Contreras-Ruiz L, Schulze U, García-Posadas L, et al. Structural and functional alteration of corneal epithelial barrier under inflammatory conditions. Curr Eye Res. 2012;37(11):971-981.

\section{Publish your work in this journal}

The Journal of Asthma and Allergy is an international, peer-reviewed open-access journal publishing original research, reports, editorials and commentaries on the following topics: Asthma; Pulmonary physiology; Asthma related clinical health; Clinical immunology and the immunological basis of disease; Pharmacological interventions and
Dovepress

new therapies. Issues of patient safety and quality of care will also be considered. The manuscript management system is completely online and includes a very quick and fair peer-review system, which is all easy to use. Visit http://www.dovepress.com/testimonials.php to read real quotes from published authors.

\footnotetext{
Submit your manuscript here: http://www.dovepress.com/journal-of-asthma-and-allergy-journal
} 